\title{
A GEOGRAPHICAL STUDY ON THE INTERNATIONAL URBAN SYSTEM BETWEEN CHINA AND JAPAN IN TERMS OF JAPANESE AFFILIATED ENTREPRISES
}

\author{
Guoqing Du \\ College of Tourism, Rikkyo University, Kitano I-2-26, Niiza, Saitama, 352-8558, Japan \\ e-mail: guoqingd@rikkyo.ne.jp
}

\begin{abstract}
The Japanese-affiliated enterprises in China are considered to have played important roles for economic development of both two countries. Looking at cities with Japanese-affiliated enterprises, this research investigates the changes in the international urban system between China and Japan. We selected 5084 direct investments items from Japan to China and investigated the spatial structure of the international urban system in 4 periods.
\end{abstract}

Key words: International Urban System, Linkage, Japanese-Affiliated Enterprise, Japan, China

\section{BACKGROUND}

\section{Changes in japanese overseas investment}

Japanese overseas investment surpassed $\$ 10$ billion (all figures are in US dollars) for the first time in 1984. It increased rapidly as the Yen appreciated after the Plaza Accords of 1985 and reached $\$ 67.54$ billion at its peak in 1989. In other words, Japanese overseas investment expanded by as many as seven times in only five years. Especially, investment toward North America increased by ten times and that to Europe by eight times. Since 1990, Japanese direct investment faltered under Japan's economic stagnation and decreased suddenly in 1992 to 34.1 billion, only half that of 1989. Investment toward North America and Europe was especially depressed (Maruyama and Narita, 1995, p.1).

Contrary to the decreasing rate of change for the previous year, direct investment toward Asia in 1992 showed an increase rate of $8 \%$. As a result, investment toward Asia extended greatly and shared $18.8 \%$ in the composition of regions in 1992.

Since 1993, Japanese investment increased again slightly. In 1994, Japanese overseas investment recovered up to $\$ 41.1$ billion as a whole. The investment toward North America kept increasing gradually while that toward Europe decreased. However, investment toward Asia increased to $47 \%$, increasing to second place, just behind North America. As a result, the share of Asia reached 24\%, its highest level to date. 


\section{Development of Japanese-Affiliated Enterprises in China}

Japanese foreign direct investment in Asia expanded with the export industry aiming for lower cost and rapidly expanding markets in different Asian regions. Expansion of investment in China can be recognized as a symbol of this movement.

Japanese investment in China increased up to $\$ 1.23$ billion at 5.4 times that of the previous year in 1987 , but decreased rapidly after the Tiananmen Square Incident to $\$ 350$ million in 1990 (Figure 1). Afterwards, investment in China increased again gradually and reached $\$ 1$ billion in 1992, with an increase rate of 1.8 times while the change rate of all other countries was negative. This development never decreased and investment in China increased to \$1.69 billion in 1993, and reached \$2.57 billion in 1994 .

Figure 1: Change in Japanese direct investment in China 1979-1999

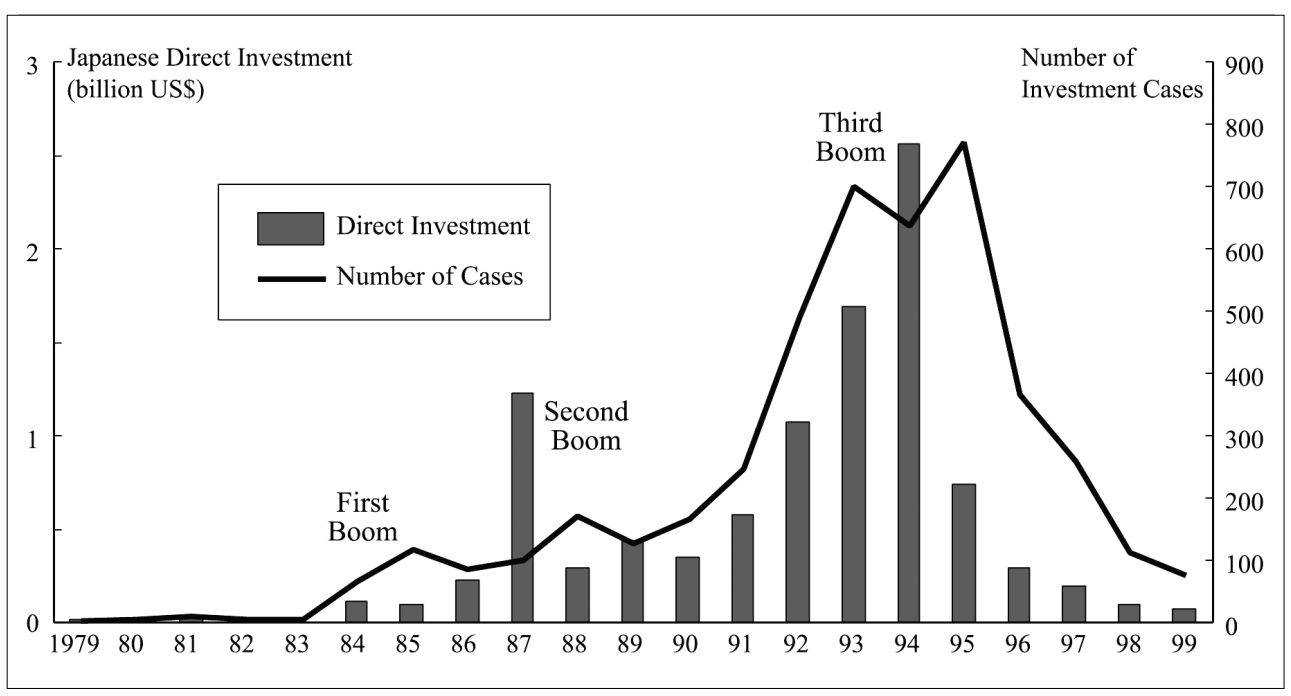

Data source: Handbook of Chinese Information 2001; List of Japanese-Affiliated enterprises 1995, 1996, 1997, 1998, 1999

China has a much larger force of cheaper labor than the countries of Asian NIEs and ASE$\mathrm{AN}$, and holds a huge market with a population of more than 1.2 billion. Therefore, the advancement of Japanese-affiliated enterprises created a development boom with not only large but also small and medium-sized enterprises of electrical machinery, fiber, and machinery industries since 1991, though there has been a serious economic stagnation in Japan in the same period.

On the other hand, the Reform and Open-Door Policy was enforced since December, 1978 in China. The enactment and maintenance of investment were prepared aimed to attract much more foreign investment afterwards. After the Joint Enterprise Law was enacted in 1979 , foreign investment has been aggressively attracted by methods including authorization of $100 \%$ foreign capital, and preferential treatment of income tax for foreign enter- 
prises. Income tax was reduced furthermore for joint enterprises in 1983 and 14 coastal cities were opened for foreign investment in 1984. As a result, the first boom of foreign investment in China occurred during the period of 1984-85, and Japanese investment to China was also accelerated.

Japanese investment to China reached \$110 million in only the year 1984 and exceeded the total investment amount of the previous five years. However, this investment boom continued for only two years under the influence of economic restraint measures of the Chinese government in 1985. In October, 1986, the Chinese government promoted the Reform and Open-Door Policy further by preferential treatments such as the enactment of "Foreign Investment Encouragement Regulations." And the second boom of foreign investment in China occurred from 1988 to the spring of 1989. During this boom, the number of Japanese investment items in China was 171 in 1988, with an increase rate of $68.3 \%$ compared with the previous year. The second investment boom continued until May, 1989 and stopped with the occurrence of the Tiananmen Square Prodemocracy Protest in June.

However, "Income Tax Law Revision" was enforced in July, 1991, and the different tax rates of foreign affiliated enterprises and $100 \%$ foreign enterprises were unified. As a whole, the $100 \%$ foreign enterprises obtained a much more preferential treatment and foreign investment in China increased once again. The total number of foreign direct investment items exceeded 10,000, and the total amount (contract base) also exceeded $\$ 10$ billion for the first time (Morita, 1992, p.64).

In addition, after the presentation of "Lecture on the Acceleration of Reform and Open-Door " by Xiaoping Deng in his inspection of the south in January, 1992, the legislation degree reform such as alleviation of domestic sale limitation for foreign enterprises and alleviation of investment were enforced. Furthermore, the Chinese government expanded the open areas from coastal areas to inland regions.

Under such a background, Japanese-affiliated enterprises began to advance to China with great power. As a result, Japan-China trade in 1992 reached its highest level of \$28.9 billion, and the Japanese investment toward China also recorded $\$ 6.2$ billion with 3,500 cases. In the following year, 1993, the advance of Japanese enterprises toward China continued and showed unprecedented power. According to the announcement of the Chinese Foreign Economic Trade Department, in 1993 the number of Japanese investments in China were 3,488 cases and the amount of investment was $\$ 2.96$ billion (contract base), which showed a higher growth rate of $93 \%$ by the number of cases and $36 \%$ by the amount of investment compared with the previous year. It can be said that the third investment boom appeared obviously in 1992.

In 1994, the number of Japanese investment cases decreased but the amount of investment reached $\$ 3.5$ billion with a rate of $18 \%$ compared to the previous year. Investigating the trend of foreign investment in China, we find that at the earlier strategy, the investment was aimed at cheaper labor force and raw material, production was done in China and then exported to other countries. With the rise of the national income of China, this tendency changed to aiming at the huge local market of China and competition for foreign investment was advanced. Consequently, Japanese direct investment in China began to increase rapidly since the latter half of the 1980's, and especially when it entered the 1990's. 
"Tentative Regulations for Foreign Investment Direction Guidance" and "Guidance Contents of the Foreign Investment Industry" were promulgated as a new guideline of the investment based on industrial policy in June, 1995. Aimed to adjust the national industrial structure, kinds of industry and regions were decided in these regulations. Investment projects were divided into four kinds: encouragement, permission, limitation and interdiction. The encouragement industries include new agriculture technology and comprehensive development, energy, traffic, important raw material, high technology, energy-saving technology, new equipment, new material, and environment preservation technology. And capital consolidating industries or technology-intensive industries was all encouraged instead of labor-intensive industries. On the regional aspect, industries that conjugated resource and labor force of the middle or western regions were encouraged.

In 1996, preferential tax measures for foreign affiliated enterprises were abolished. Disordered expansion and all azimuths opening for foreign investment were converted into qualified investment along with new industry policy. Influenced by the Asian Monetary Crisis and changes in China's investment policies, foreign direct investment toward China showed a decreasing tendency since 1997. The direct investment acceptance of China in 1998 presented an extremely low expansion both by contract and execution base. Especially, the increase rate of execution base changed from two digit in 1996 to one digit in 1997 , and then to $0.4 \%$ in 1998 .

\section{RESEARCH PURPOSE}

It is thought that the advancement of Japanese-affiliated enterprises in China is accomplishing the key role of economic development for both China and Japan. It can be understood that the activities of an enterprise are assumed to be spatially and temporally enlarged to their maximum degree on the concept of "Global Management." Such activities, in a sense, cross the border of countries, and conversely countries are influenced by the development of such activities. Therefore, the international urban system relation of two countries is formed by the advancement of enterprise activities.

It is important to investigate the geographical aspect of the international urban system based on the cities where enterprises are located. The purpose of this research is to clarify the spatial structure of the international urban system in terms of the Japanese-affiliated enterprises' advancement in China.

5,085 Japanese direct investment cases, whose investment year, location in China, address in Japan, and amount of investment can all be identified, were selected from the 14,857 cases dating from 1980 to 1999 in the "List of the Japanese-Affiliated Enterprises in China, 1999" as analysis samples for this research.

In our analysis, we use the total direct investment amount between two cities as the linkage to investigate the structure of international urban system in the four periods according to the change in the amount of direct investment and the number of cases (Figure 2). In the first period of 1980-85, the investment amount is $\$ 0.75$ billion and the number of investment cases was 110 . According to the change rates of the amount of investment for each, 
the first period was an unstable period. We can find both the highest rate of change $(1446 \%$ of 1984) and the lowest one (3\% of 1982) from 1980 to 1999 in this period. In the second period of 1986-90, the development of Japanese investment showed a relatively stable increasing pattern, and the investment amounted to $\$ 1.89$ billion and 490 cases. The third period of 1991-95 is a significant developing period with higher increasing rates. Except for the year 1993, all the years showed rates of change above $130 \%$. The total of investment amounted to $\$ 13.91$ billion and 3538 cases, 6 times higher than the previous period. The fourth period of 1996-99 can be recognized as a decreasing period with change rates lower than $60 \%$ each year. But the investment amounted to $\$ 3.47$ billion and 946 cases, which are all more than that of the second period.

Figure 2: Changes in research samples (1980-1999)

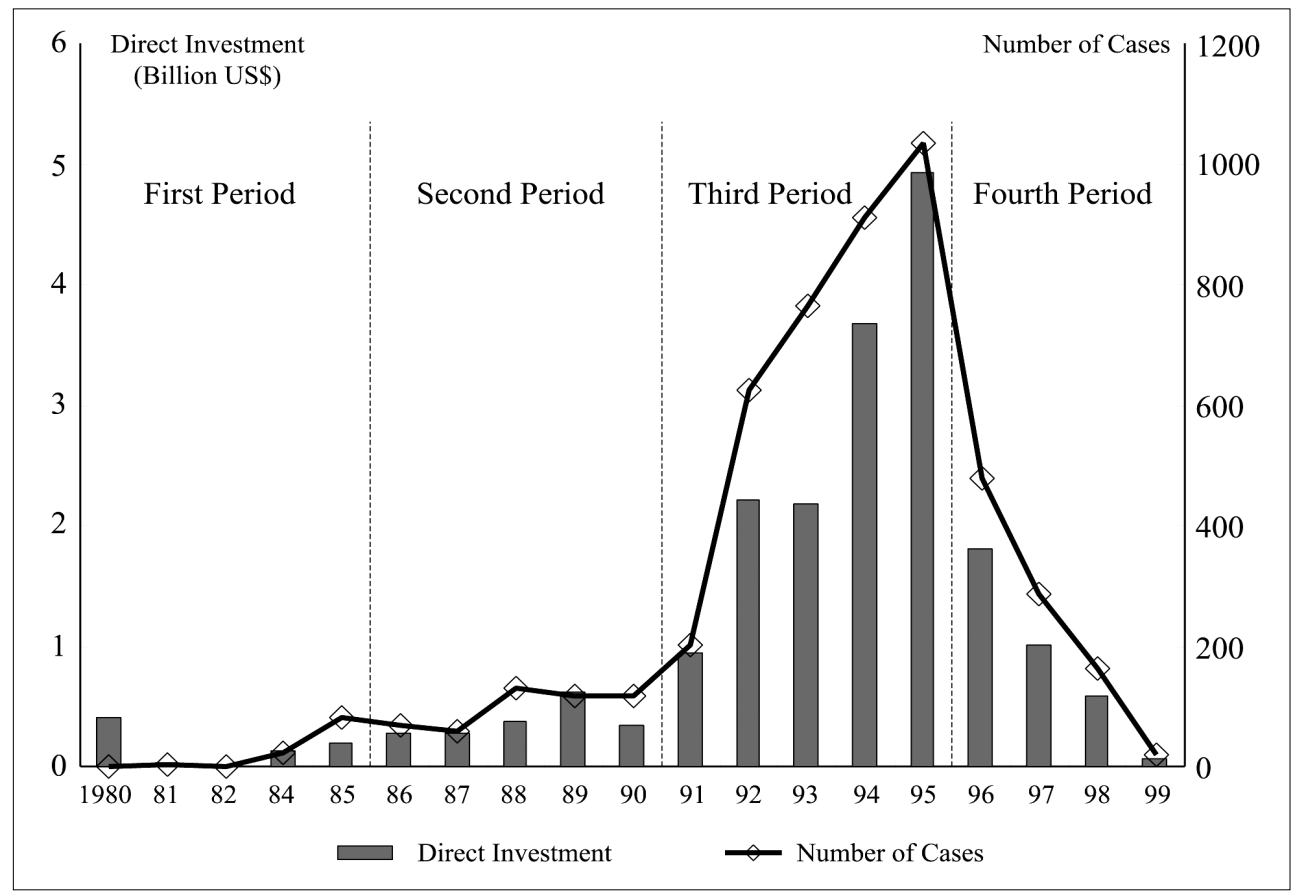

\section{SPATIAL STRUCTURE OF INTERNATIONAL URBAN SYSTEM OF CHINA AND JAPAN}

Figure 3 shows the rank-size distribution of the top Chinese and Japanese cities by the total amount of investment. The most significant feature is the primacy of Tokyo. Investment from Tokyo is $\$ 4.58$ billion, which is 5.6 times that of the second city, Osaka, in Japan. The same rate is only 2.2 times that between the first city Shanghai and the second city Beijing in China. By the structure of the top 20 cities, Japanese cities present a pattern of concentra- 
tion in metropolitan areas, while Chinese cities show a development of multi-center style. For example, Tokyo ranks 1 and its suburban city Chofu ranks 3, Osaka ranks 2 and its suburban city Kadoma ranks 4 . The same pattern can also be found by Nagoya's rank 7 and its suburban city's rank 8. It can be realized that the development of metropolitan areas is more significant than the individual center cities. On the Chinese side, the development of individual center cities is quite significant. For example, the top 5 cities, Shanghai, Beijing, Dalian, Tianjin and Qingdao, are all individual center cities.

Figure 3: Rank and size distribution of top 20 Chinese and Japanese cities

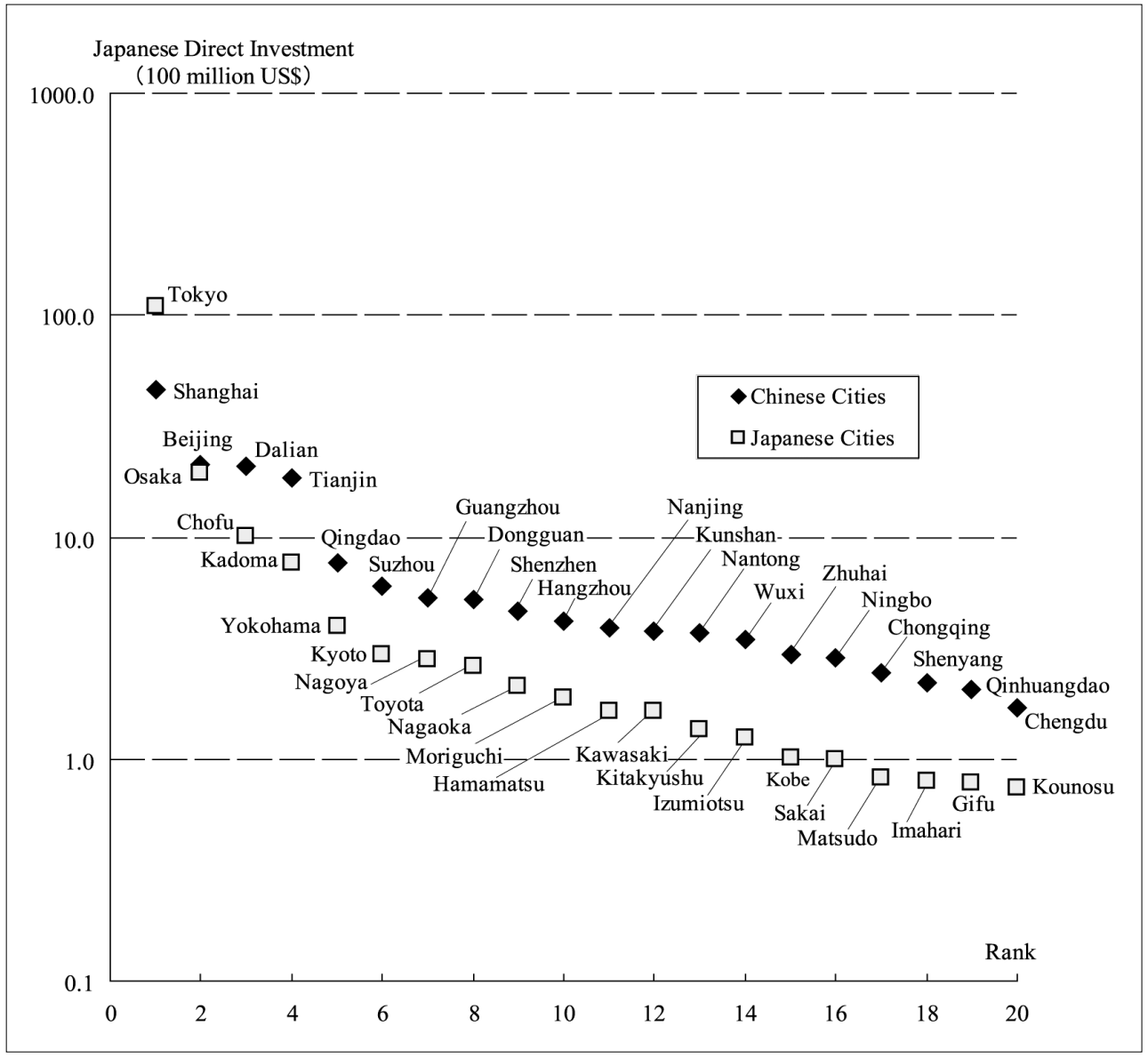

The primacy of Tokyo can also be testified with the rank-size distribution of the top 20 linkages (Figure 4), among which there are 12 linkages from Tokyo. Furthermore, the top four linkages are all from Tokyo.

In the first period of 1980-85, huge investment linkages existed only between Tokyo and China's big harbor cities such as Tianjin, Shanghai and Fuzhou (Figure 5). The inves- 
tment was all concentrated among the major cities both in China and Japan. Especially, concentration in Tokyo was a significant feature in Japan. The investment from Tokyo amounted to $\$ 670.8$ million, which is almost 31 times that of the second city Osaka ( $\$ 32.0$ million) in Japan. In China, there was no city which amounted to more than $\$ 500$ million, and the highest two cities were Tianjin (\$418.7 million) and Shanghai (\$171.6 million). There were seven linkages above $\$ 10$ million, among which the 5 highest linkages were all from Tokyo such as Tokyo-Tianjin (\$405.2 million), Tokyo-Shanghai (\$170.4 million), Tokyo-Fuzhou (\$31.5 million), Tokyo-Beijing (\$23.9 million) and Tokyo-Chongqing (\$17.2 million), and the following two are Moriguchi-Foshan (\$11.5 million) and OsakaTianjin (\$11.1 million).

Figure 4: Rank and size structure of top 20 linkages

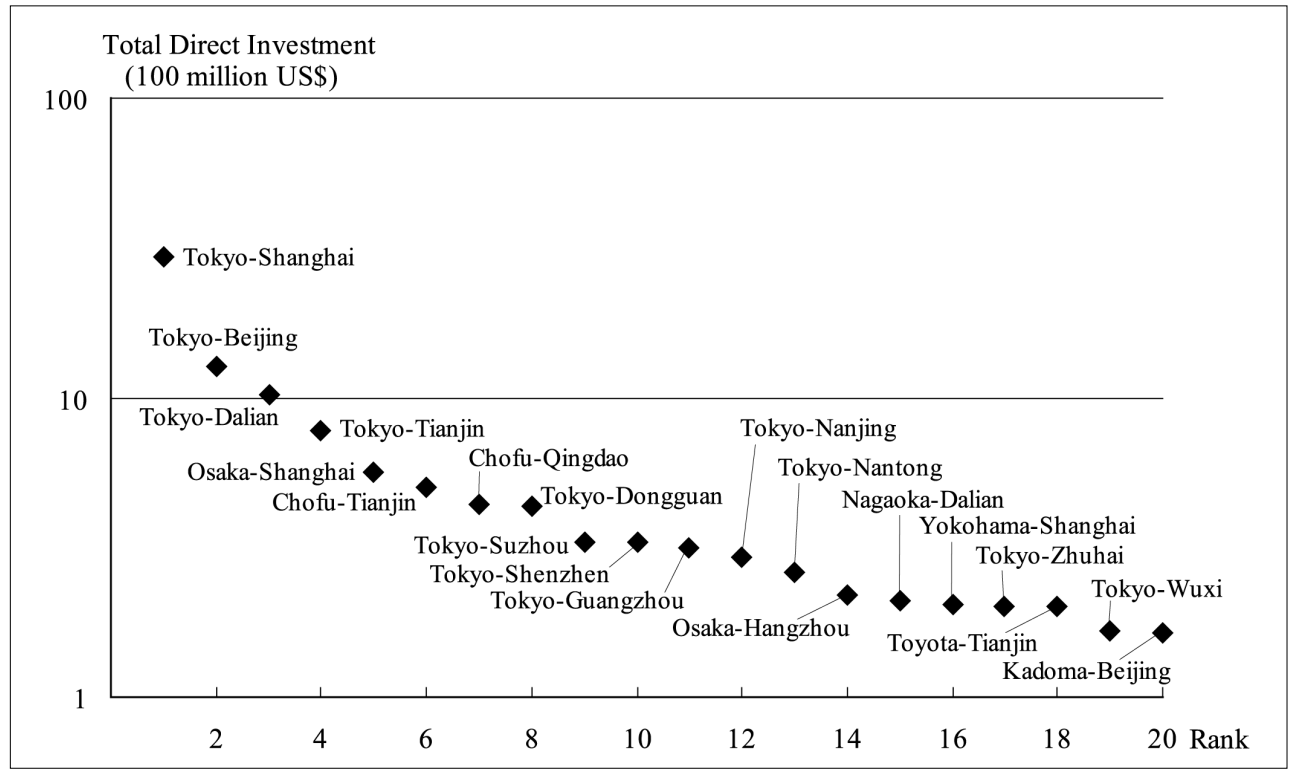

Figure 6 shows the structure of international urban system in the second period of 1986-90. Japanese investment spread to the more coastal cities such as Dalian, Beijing, Zhuhai and Shenzhen, though the tendency of concentration in the coastal area didn't change. However, the tendency of concentrations in individual cities had changed into the formation of urban groups or systems based on individual center cities such as Beijing, Shanghai and Guangzhou. Besides Tokyo (\$1.32 billion) in Japan, Dalian (\$599.3 million) in China also amounted to more than $\$ 500$ million. The following 5 higher cities were all Chinese cities: Beijing (\$273.9 million), Shanghai (\$223.4 million), Zhuhai (\$132.3 million), Tianjin (\$102.6 million). The second highest Japanese city, Osaka (\$87.9 million) showed less of a gap compared with Tokyo than in the previous period. Although strong linkages of over $\$ 100$ million were still remarkably limited to Tokyo, the activation of investment from Osaka and its suburban cities such as Takatsuki and Kadoma are also remarkable. The 
investment concentration in Chinese coastal areas can also be testified according to the distribution of linkages. Except for the investment from Tokyo to Urmuqi (\$79.2 million), the other 13 investment linkages above $\$ 30$ million were all towards coastal cities: Dalian (Tokyo-Dalian \$430.0 million; Matsudo-Dalian \$38.4 million; Shizuoka-Dalian \$37.2 million), Shanghai (Tokyo-Shanghai \$157.2 million), Beijing (Tokyo-Beijing \$136.7 million; Osaka-Beijing \$41.0 million; Takatsuki-Beijing \$40.6 million; Kadoma-Beijing 40.6), Zhuhai (Tokyo-Zhuhai \$132.3 million), Shenzhen (Tokyo-Shenzhen \$118.2 million), Tianjin (Tokyo-Tianjin \$70.6 million), Shantou (Tokyo-Shantou \$36.2 million) and Qin-gdao (Tokyo-Qingdao \$31.2 million).

Figure 5: Spatial structure of international urban system of China and Japan (1980-1985)

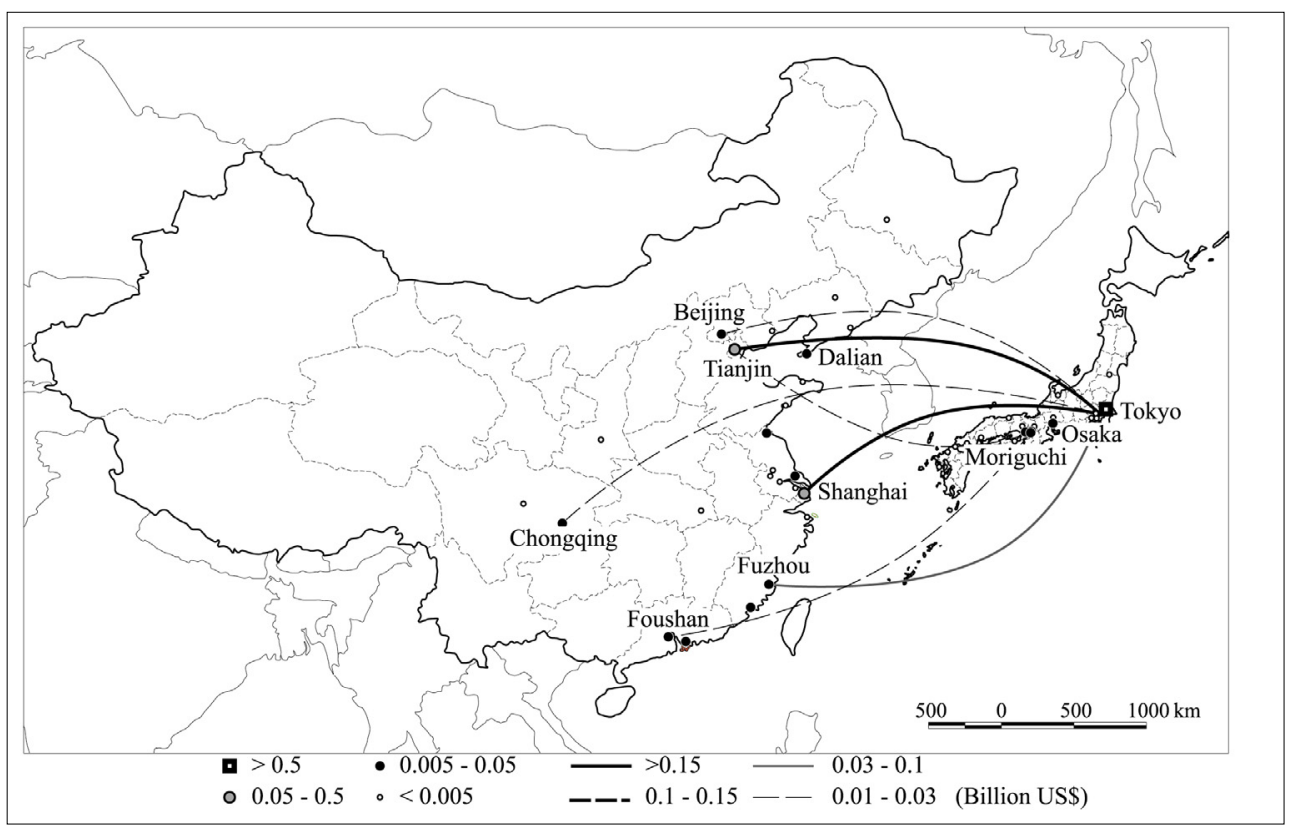

In the third period of 1991-95, Japanese-affiliated enterprises in China increased significantly, and a lot of strong linkages appeared (Figure 7). In Japan, though the primary position of Tokyo ( $\$ 6.98$ billion) didn't change, an investment boom can also be identified in suburban cities such as Chofu ( $\$ 1.00$ billion), Yokohama (\$339.4 million) in Tokyo Metropolitan area as well as Osaka Metropolitan area (Osaka, \$1.36 billion) and Nagoya Metropolitan area (Nagoya, $\$ 172.3$ million). On the other hand in China, besides the rapid increase of investment in Shanghai ( $\$ 3.52$ billion), Dalian ( $\$ 1.26$ billion), and Beijing ( $\$ 1.19$ billion) metropolitan areas, the development of Japanese investment in the Shandong Peninsula centered on the big city Qingdao (\$627.9 million) is also remarkable. Furthermore, the enterprise had been advanced to inland cities such as Chongqing (\$197.3 million), Chengdu (\$69.5 million) and Xi'an (\$50.4 million) with the investment from Tokyo. Compared with the previous period, the number of linkages over $\$ 150$ million increased from 2 
to 16 , and that of linkages between $\$ 100$ and $\$ 150$ million increased from 3 to 8 . Further more, all the 5 linkages over $\$ 100$ million were all from Tokyo in the previous period, but in this period, besides the 13 linkages from Tokyo ${ }^{1}$, we can also find linkages from Chofu (Chofu-Tianjin \$502.9 million; Chofu-Qingdao \$438.1 million), Osaka (Osaka-Shanghai \$426.7 million; Osaka-Hangzhou \$208.6 million; Osaka-Dalian \$106.2 million), Nagaoka (Nagaoka-Dalian \$209.7 million), Yokohama (Yokohama-Shanghai \$202.9 milli-on), Kadoma (Kadoma-Guangzhou \$125.2 million; Kadoma-Dalian \$120.8 million; Kadoma-Shanghai $\$ 118.6$ million) and Kyoto (Kyoto-Dalian \$100.0 million).

Figure 6: Spatial structure of international urban system of China and Japan (1986-1990)

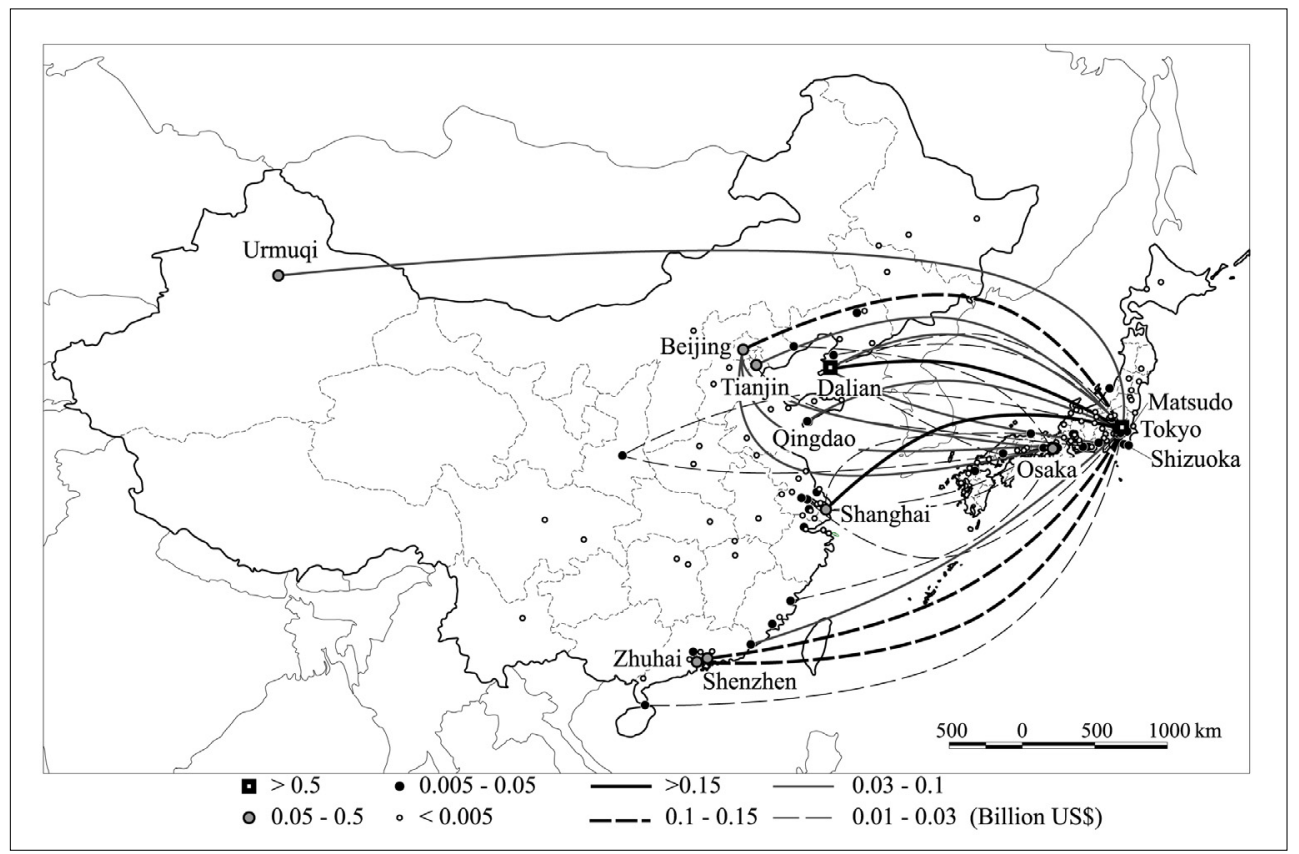

During the forth period of 1996-99, the tendency of concentrating in the primary city Tokyo ( $\$ 1.90$ billion) kept being significant even though investment developed stagnantly, but the higher function of Osaka ( $\$ 464.1$ million) and Nagoya (\$89.0 million) can also be recognized. In China, infiltration of investment to the interior became a remarkable feature as a result of new industry policy. Advancement of enterprises expanded to Chengdu (\$91.3 million), Guiyang (\$60.3 million), Xi'an (\$33.7 million), Chongqing (\$28.5 million) and Kunming ( $\$ 15$ million) with the investment from the huge center cities or their suburban cities. The shift of investment from the coastal areas to inland areas can be recognized as a result of the income increase, competition among foreign investment and difficulty of secu-

\footnotetext{
${ }^{1}$ Tokyo-Shanghai 2180.4; Tokyo-Beijing 648.1; Tokyo-Dalian 441.2; Tokyo-Dongguan 436.1; Tokyo-Suzhou 288.2; Tokyo-Tianjin 271.6; Tokyo-Nanjing 258.3; Tokyo-Nantong 209.3; Tokyo-Guangzhou 187.8; Tokyo-Shenzhen 177.2; Tokyo-Qinhuangdao 140.9; Tokyo-Wuxi 128.6; Tokyo-Yantai 110.5. (Unit: million US dollars)
} 
ring a labor force in the coastal area. The number of linkages over $\$ 150$ million decreased to three, among which there is one from Toyota to Tianjin amounting to $\$ 165.1$ million. Such dispersion from Tokyo can also be found by the existence of one linkage from Osaka to Shanghai (\$115.9 million) with the other two from Tokyo (Tokyo-Dalian \$143.9 million; Tokyo-Guangzhou \$123.5 million) among the three linkages of \$100-150 million.

Figure 7: Spatial structure of international urban system of China and Japan (1991-1995)

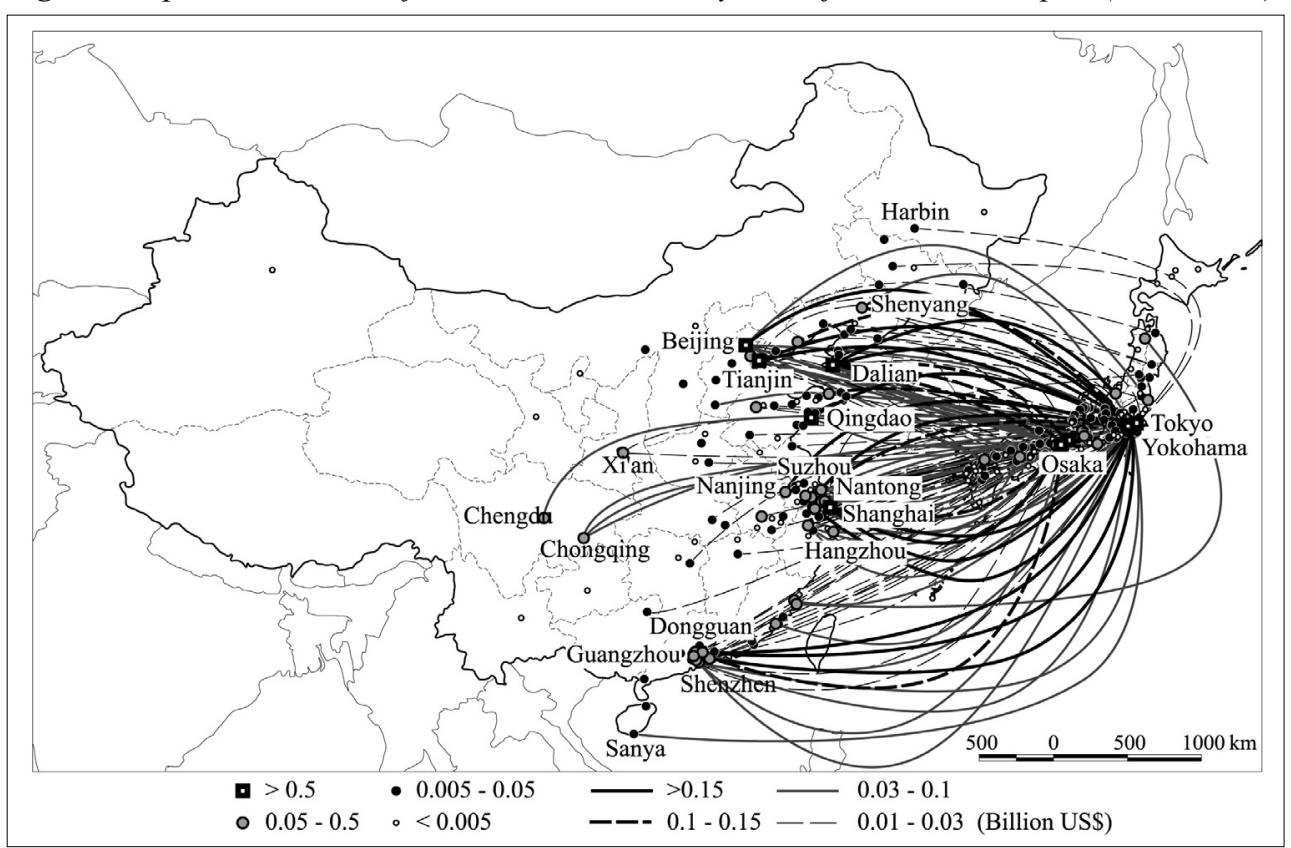

\section{CONCLUSION}

In 1986, Japanese investment in the three largest cities, Beijing, Tianjin and Shanghai accounted for 44\%, and that in Guangdong, Fujian and Liaoning provinces accounted for only $34 \%$. On the other hand, American investment in the three largest cities was only $27 \%$, and that in the coastal cities was $41 \%$, the remaining $32 \%$ was invested in the inferior inland areas. This tendency or feature of Japanese investment also has a great influence on the spatial structure of the international urban system of China and Japan.

If we divide China's coastal areas into three regions: Northern China, Changjiang Delta, and Southern China, the investment acceptance (execution base) of Southern China occupies half, and the total of these three areas occupies $90 \%$ of the whole nation (Maruyama and Narita, 1995, p.12). Such tendency of concentration and preceding development in the coastal area can also be found by the distribution of GNP and exports. Especially in the Northern China area, Liaoning province obtained an economic structure of heavy machinery industry and national government owned corporations, accepting great amounts of Ja- 
panese direct investment and exporting products to Japan from big cities such as Dalian. Contrary to that, Guangdong province in Southern China obtained a structure of light industry and non-government owned corporations.

With respect to the acceptance of direct investment, the proportion of labor intensive assembly processing for export is predominant. Moreover, in the big cities in the Changjiang Delta such as Shanghai, investment related to the distribution industry and financial business for the development of the domestic market has increased rapidly.

By the analysis above, we can find that there are the following features of the international urban system by Japanese-affiliated enterprises.

1) Investment starts from high-ranking cities in the recipient country, and infiltrates to subordinate cities.

2) Strength of linkage is proportional to the hierarchy of the recipient city.

3) The range area of investment infiltration is proportional to the hierarchy of the investment city.

(This project is funded by Japan Society for the Promotion of Science)

\section{References}

Maruyama, K. and Narita, Y., 1995: The Asian Strategy of Japanese Enterprises: A Subject of International Labor Division and Symbiotic Relationship. Tokyo: Kotokusha.

Mitsubishi Research Institute, 2001: Handbook of Chinese Information 2001. Tokyo: Sososha. 556p.

Morita, Y., 1992: Overseas Presence of Japanese Enterprises: Direct Overseas Investment of Small and Medium-Sized Enterprises. Tokyo: Dobunkan.

Toyo Keizai shinhosha, 1996: List of Japanese-Affiliated Enterprises 1996.

Toyo Keizai shinhosha, 1997: List of Japanese-Affiliated Enterprises 1997.

Toyo Keizai shinhosha, 1998: List of Japanese-Affiliated Enterprises 1998.

Toyo Keizai shinhosha, 1999: List of Japanese-Affiliated Enterprises 1999.

Toyo Keizai shinhosha , 1995: List of Japanese-Affiliated Enterprises 1995. 